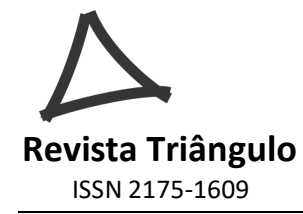

\title{
PODER, GEOPOLÍTICA E MOBILIZAÇÃo DO CONHECIMENTO: A UNIVERSIDADE EM QUESTÃO
}

\author{
POWER, GEOPOLITICS AND MOBILIZATION OF KNOWLEDGE: THE UNIVERSITY IN QUESTION \\ PODER, GEOPOLÍTICA E MOVILIZACIÓN DEL CONOCIMIENTO: LA UNIVERSIDAD EN CUESTIÓN
}

Ivanise Monfredini

E-mail: imonfredini@uol.com.br Universidade Católica de Santos

Ricardo Pérez Mora

E-mail: cucea@udg.mx

Universidad de Guadalajara - México

\begin{abstract}
RESUMO
O artigo retoma algumas aportações dos conceitos de geopolítica do conhecimento, em particular sobre as lógicas de distribuição do poder e sua relação com o conhecimento para tratar da relação entre os setores populares e a universidade a partir do conceito de "mobilização do conhecimento" (Pérez Mora, Cruz Sánchez, \& García Ponce de León, 2018; Pérez Mora \& Inguanzo Arias, 2018). Partindo de romper esquemas estáticos da distribuição de poder e saber, se propõe o conceito, o qual parte do dinamismo do conhecimento e o potencial que se gera em sua mobilização com os diferentes atores, colocando especial ênfase nos setores sociais tradicionalmente excluídos dos direitos cidadãos, sociais, culturais e econômicos.
\end{abstract}

PALAVRAS-CHAVE: Geopolítica do conhecimento. Mobilização do conhecimento. Distribuição do poder.

\begin{abstract}
The article takes up some contributions of the concepts of geopolitics of knowledge, in particular on the logic of power distribution and its relationship with knowledge to deal with the relationship between popular sectors and the university based on the concept of "mobilization of knowledge" (Pérez, Mora, Cruz Sánchez, and Garcia Ponce de León, 2018, Pérez Mora and Inguanzo Arias, 2018). Starting from breaking any static scheme of the distribution of power and knowledge, the concept is proposed, which starts from the dynamism of knowledge and the potential that is generated in its mobilization with the different actors, placing special emphasis on traditionally excluded social sectors of citizen, social, cultural and economic rights.
\end{abstract}

KEYWORDS: Geopolitics of knowledge. Knowledge mobilization. Power distribution.

\section{RESUMEN}

El artículo retoma algunas aportaciones de los conceptos de geopolítica del conocimiento, en particular sobre las lógicas de distribución del poder y su relación con el conocimiento para tratar la relación entre los sectores populares y la universidad a partir del concepto de "movilización del conocimiento" (PÉREZ MORA;CRUZ SÁNCHEZ; GARCÍA PONCE DE LEÓN, 2018; PÉREZ MORA; INGUANZO ARIAS, 2018). Partiendo de romper cualquier esquema estático de la distribución del poder y saber, se propone el concepto, el cual parte del dinamismo del conocimiento y el potencial que se genera en su movilización con los diferentes actores, poniéndo un especial énfasis en los sectores sociales tradicionalmente excluidos de los derechos ciudadanos, sociales, culturales y económicos.

PALABRAS-CLAVE: Geopolítica del conocimiento. Movilización del conocimiento; Distribución del poder. 


\section{INTRODUÇÃO}

A ordem atual, seja quando nos refiramos à ordem econômica, política ou social, explica-se cada vez mais a partir de teorias e modelos que ultrapassam as fronteiras locais e são configurados por meio de lógicas globais. Termos como globalização e mundialização evidenciam a importância da ordem geopolítica de grande escala na compreensão das sociedades atuais.

La era del espacio fue la época en que las fronteras se podían impermibilizar, pero ahora, tras el 11 de septiembre, todo esto ha cambiado, ya que nadie puede desvincularse del resto del mundo. Los lugares ya no protegen, y las amenazas y la seguridad se han convertido en asuntos extraterritoriales (y difusos) que evaden soluciones territoriales (y concretas) (BAUMAN 2002, apud SLATER, 2008, p.38).

O liberalismo e a economia de mercado explicam em grande parte a tendência para a concorrência global sobre a concorrência local e as tecnologias de informação e comunicação aumentam e aceleram essa tendência. No entanto, dada essa tendência expansiva, as transformações locais, o papel dos estados-nações, os nacionalismos, a regionalização não desaparecem completamente. Coexistem, face às fortes tendências globalizadoras, e é a partir dessa coexistência que se configuram histórias e realidades particulares, em cada contexto e em cada momento histórico que vão além das velhas antinomias norte-sul, centro-periferia, inclusão-exclusão, global-local, modernidade-tradição. Se geram situações de exclusão em contextos considerados "incluídos", encontramos pólos de desenvolvimento no sul e cinturões de miséria em certos contextos, no norte. Dube usa o neologismo de "modernidades coloniais" para "volver palpables ciertas consideraciones relativas a las conjunciones críticas entre el poder colonial y las modernidades vernáculas, así como conexiones cruciales entre una modernidad dominante y los pasados subalternos" (DUBE, 2004, p.15).

A geração, distribuição, organização e aplicação do conhecimento obedece a regras semelhantes e há, certamente, uma importante conexão entre conhecimento e poder que pode ser analisado do ponto de vista da geopolítica: a partir do momento em que o conhecimento se distingue em termos de região, de domínio, de implantação, de deslocamento, de transferência, o processo pode ser analisado da perspectiva em que o conhecimento funciona como poder e traz de volta para ele, os efeitos. "Existe una administración del saber, una política del saber, relaciones de poder que pasan a través del saber y que inmediatamente, si 
se las quiere describir, reenvían a estas formas de dominación a las que se refieren nociones tales como campo, posición, región, territorio." (FOUCAULT, 1992, p.125).

$\mathrm{O}$ artigo retoma algumas contribuições dos conceitos de geopolítica do conhecimento, em particular sobre as lógicas de distribuição do poder e sua relação com o conhecimento, para propor estratégias de empoderamento de setores vulneráveis, com base no conceito de "mobilização do conhecimento" (PÉREZ MORA, CRUZ SÁNCHEZ e GARCIA PONCE DE LEÓN, 2018, PÉREZ MORA e INGUANZO ARIAS, 2018). Toma a Universidade como instituição moderna, concebida historicamente como lugar de produção de ciência e alta cultura (SANTOS, 1997). Ao quebrar qualquer esquema estático de distribuição do poder e do conhecimento, o conceito de mobilização do conhecimentos é proposto, partindo do dinamismo do conhecimento e do potencial que se gera em sua mobilização com os diferentes atores, na relação com a universidade, com especial ênfase nos setores sociais tradicionalmente excluídos dos direitos de cidadania, direitos sociais, culturais e econômicos.

\section{DO EUROCENTRISMO MODERNO AO PROJETO EPISTEMOLÓGICO DA TRANSMODERNIDADE E DO PÓS-OCIDENTALISMO}

Um dos principais focos de análise da geopolítica e, em particular, da geopolítica do poder gira em torno das formas de dominação exercidas por alguns estados em detrimento de outros. Entre elas estão as formas pelas quais se desenvolveu a dominação europeia a partir da colonização. "La historia de las Américas, de todas las Américas y del Caribe, están atravesadas e interconectadas por el colonialismo y por lo que Aníbal Quijano identificó como la colonialidad del poder" (MIGNOLO, 2004, p.228). A colonialidade refere-se à continuidade das formas coloniais de dominação após o fim das administrações coloniais (GROSFOGUEL, 2002, p. 205). A América Latina tem sido vítima desses colonialismos e imperialismos que se impõem fortemente em nossos países, mas também geraram um importante pensamento intelectual que questiona o papel dos países centrais como centro da história, do poder econômico, político e epistêmico do mundo.

Um dos aspectos da crítica gira em torno do conceito de eurocentrismo, um conceito que coloca a Europa como centro e motor da civilização, que tem implicações econômicas, culturais e políticas, entre outras. O primeiro eurocentrismo, seguindo Dussel, foi formulado no final do século XIII com o Iluminismo francês e inglês e os românticos alemães, e que 
"reinterpretó la historia mundial toda entera, proyectando Europa hacia el pasado, e intentando demostrar que todo había sido preparado en la historia universal para que dicha Europa fuera el fin y el centro de la historia mundial" (DUSSEL, 2004, p.202). "El primer eurocentrismo es el de Hegel y Weber, quienes suponen la superioridad de Europa, superioridad probada por factores puramente internos de la misma Europa."(p. 205).

Dussel argumenta que essa Europa ideal-imaginária, tão influente, passou a ser desafiada pelos modos de entender o sistema global proposto por Immanuel Wallerstein (DUBE, 2004b, p.38, DUSSEL, 2004, p.203). A noção do sistema global de Wallerstein revelou que a dominação do mundo moderno pelos europeus tinha apenas 500 anos e que, além disso, essa posição central depende preponderantemente da descoberta das Américas. Com isso se "limitaba la centralidad de Europa a los cinco últimos siglos y le quitaba el áurea de centro eterno de la historia mundial" (DUSSEL, 2004, p.203). O sistema-mundo criou a Europa graças à invasão do continente americano chamada descobrimento. Este segundo eurocentrismo, que superou o primeiro, "piensa todavía desde Europa, aunque acepta que ésta logró el dominio por factores exteriores (por ejemplo, los metales preciosos americanos), lo que le permitirá triunfar en la competencia con el mundo musulmán, África y Asia desde 1492" (DUSSEL, 2004, p. 205). Dussel enfatiza que a modernidade é um elemento primordial para a centralidade européia no segundo eurocentrismo. Mignolo aponta o caminho pelo qual "el brillo de la modernidad nos ocultaba la colonialidad. Pensábamos que el periodo colonial se había terminado convencidos por la ideología nacionalista con que se escribia la historia continental" (MIGNOLO, 2004, p.227). O autor nos faz ver que a colonialidade ainda está viva hoje e domina o período de construção nacional, e que ainda hoje está ativa na colonialidade global. Utiliza o termo para se referir ao mesmo tempo a diferentes momentos históricos identificados como colonialismo, imperialismo e globalização. (MIGNOLO, 2004, p.232).

Dussel problematiza as abordagens de Wallerstein no conceito de sistema-mundo e o chamado segundo eurocentrismo, e argumenta que, na realidade, a centralidade da Europa é reduzida a apenas dois séculos. Para o autor, a hegemonia da Europa se dará graças à Revolução Industrial, baseada ideologicamente no fenômeno do iluminismo e do movimento romântico (DUSSEL, 2004, p.215). A partir dessa ideia, ele sugere que há momentos culturais fora dessa modernidade, outras culturas desprezadas, não valorizadas: 

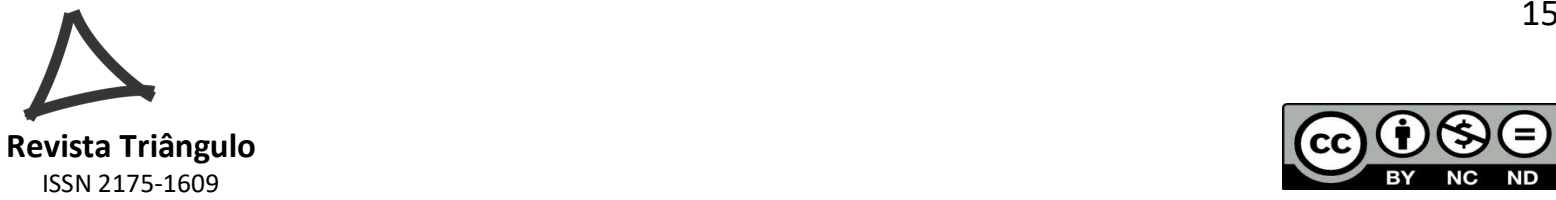

Con el impacto de la modernidad Europea desde hace poco en las múltiples culturas del planeta (piénsese en las culturas china, del sudeste asiático, hindú, musulmana, bantú, latinoamericana), todas ellas producen una respuesta variada al "challenge" moderno e irrumpen renovadas en un horizonte más allá de la modernidad" (DUSSEL, 2004, p. 201)

Ele chama essa realidade de "transmodernidade" que a distingue da pós-modernidade, argumentando que esta última ainda é um último momento da modernidade ocidental. Ele aponta que as críticas pós-modernas à modernidade ainda estão confinadas em premissas eurocêntricas duradouras "lo post de la posmodernidad no le quita el eurocentrismo". Diante disso, Dussel encontra futuros alternativos dentro dos termos e da ética da transmodernidade, incorporando culturas da maior parte da humanidade que foram excluídas da modernidade.

Hablar de transmodernidad exigirá una nueva interpretación de todo el fenómeno de la modernidad, para poder contar con momentos que nunca estuvieron incorporados a la modernidad europea, y que subsumiendo lo mejor de la modernidad europea y norteamericana que se globalizan, afirmará fuera de ella componentes esenciales de sus propias culturas excluidas, para desarrollar una nueva civilización futura, la del siglo XXI. (DUSSEL, 2004, p. 205).

Através da categoria de "exterioridade" propõe-se investigar a positividade cultural não incluída pela modernidade, não a partir dos pressupostos de uma pós-modernidade, mas do que ele chama de transmodernidade. Ou seja, se trata de um processo que se origina "se mobiliza" a partir de outro lugar, diferente da modernidade européia e norteamericana (DUSSEL, 2004, p. 221)

\begin{abstract}
Para la exterioridad negada y excluida por la expansión moderna de la Europa hegemónica hay culturas actuales que son anteriores, que se han desarrollado junto a la modernidad europea, que han sobrevivido hasta el presente y que tienen todavía potencial de humanidad suficiente para desarrollar sus propias potencias a fin de gestar una multiculturalidad, una pluralidad cultural futura posterior al término de la modernidad y el capitalismo: esas culturas vivientes y fecundas, diferentes y creativas no son simplemente una cultura posmoderna, ya que ésta es sólo una última etapa de la modernidad, sino que son culturas desarrolladas en un horizonte transmoderno, como un más allá de toda posibilidad interna de la sola modernidad.
\end{abstract}

Mignolo, seguindo Dussel, aponta que a transmodernidade vai além da caracterização histórica que inclui o que foi entendido até agora como modernidade geo-historicamente localizada na Europa, mas também as modernidades periféricas e subalternas que permaneceram ocultas na construção eurocêntrica da modernidade. (MIGNOLO, 2004, p.229) 
concorda com Dussel que a crítica da modernidade mantém um silêncio epistêmico sobre os conhecimentos que foram suprimidos ou subalternizados (p.230). Com base nisso, o autor enfatiza as possibilidades de um projeto epistemológico para o futuro baseado em seu conceito de razão pós-ocidental com o qual ele se refere à possibilidade de pensar processos de transformação não-eurocêntricos. Isto é, "producir conocimiento con perspectiva de futuro a partir de categorías de pensamiento que fueron subalternizadas y categorizadas como racionales o no racionales a lo largo de la construcción y expansión del mundo moderno/colonial" (MIGNOLO, 2004, p. 251). Para o autor, essa distribuição das formas de conhecimento entre racional e não-racional é uma distribuição na qual a colonialidade do poder é exercida, onde a diferença colonial foi criada e reproduzida. A partir disso, Mignolo (2004, p. 255) "anuncia su contribución a un futuro transmoderno y postoccidental a partir de la emergencia de la epistemología fronteriza afincada en y desde la diferencia colonial”.

\section{DA UNIVERSIDADE MODERNA À UNIVERSIDADE NEOLIBERAL: DESAFIOS E POSSIBILIDADES}

"iQue tremendo determinismo pesa sobre el conocimiento; Nos impone qué hay que conocer, cómo hay que conocerlo, lo que no hay que conocer. Manda, prohíbe, traza las rutas, establece balizas, alza alambradas de espinas y nos conduce allí donde debemos ir" (MORIN, 2001).

A Universidade cabe perfeitamente na alusão de Morin (2001) sobre o conhecimento. Instituição milenar, ao longo do tempo vai perdendo o "espírito da universalidade" que marcou a sua origem na idade média, no trabalho do mestre universitário, como relata Ruy Nunes, citado por Souza (1996). Durante os séculos XIV e XV, que marca o nascimento da Universidade moderna, as corporações mestre-alunos medievais foram substituídas pelo humanista e pelo "senhor da cátedra universitária" escolhidos por nepotismo ou indicação política. Essa mudança, associada à criação de um número muito maior de universidades atreladas aos Estados, resultou na perda de algumas características da universidade medieval, dentre elas, a autonomia e a universalidade presentes no trabalho do mestre universitário (SOUZA, 1996). 

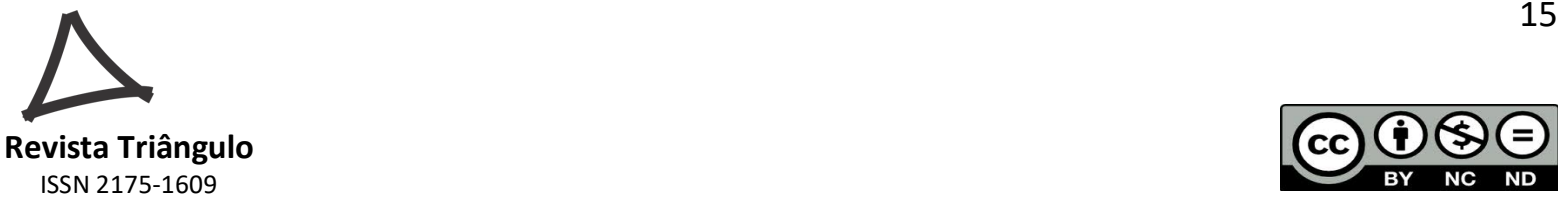

Na Europa, a representação da Universidade como lugar de "verdades" cientificamente produzidas, é fenômeno que se estabeleceu principalmente entre os séculos XVIII e XIX ${ }^{1}$. A Universidade tornou-se instituição isolada das demais, reconhecida como lugar privilegiado para a para formação de elites, lugar de criação de alta cultura e conhecimento científico, em dessintonia com as exigências sociais então emergentes (SANTOS, 1997), relacionadas com a industrialização e complexificação social. Dessa perspectiva, a crise é fenômeno que acompanha e se incrusta na própria identidade da universidade, que se institui como lugar em constante mudança. Historicamente e com a constituição dos Estados Modernos a Universidade se estabeleceu como complexo social imbricada às relações sociais de produção. Em diferentes momentos históricos, diferentes setores sociais apontaram a sua crise. As saídas sugeridas passaram, entre outros aspectos, por propostas de mudanças organizacionais, de controle do Estado e da sociedade sobre a universidade. A despeito de sua constante crise, a significação social de instituição moderna, de criação de alta cultura e ciência, segue. Entre os séculos XVIII e XIX, é que ganha força a ideia de que é nessa instituição o lugar da ciência. No projeto da modernidade, construído em torno do Estado - que exerce o monopólio da violência física - caberia a Universidade produzir a identidade da elite forjada no humanismo iluminista, que, nas palavras de Magalhães remete à valorização do homem e do conhecimento:

A fundação narrativa da modernidade que é possível encontrar em Hobbes, Locke, Adam Smith, Rousseau, Hegel, Marx, etc., centrando o tempo e a história modernos em torno do Estado, do mercado ou da comunidade, teve os seus equivalentes no que diz respeito às instituições de ensino superior em von Humboldt e no cardeal Newman, para mencionar apenas estes dois. Assumindo, não obstante, diferentes matizados, os discursos destes autores possuem algo de muito forte em comum: a sua fé moderna no Homem, no Conhecimento (enquanto Ciência, Verdade) e na História. (MAGALHÃES, 2006, p.17)

Essa narrativa persiste, porém, com alterações no seu núcleo significativo. Em meados do século XX, após a segunda guerra mundial ocorre nova ampliação na quantidade de universidades. As novas universidades criadas nesse período, assim como as seculares, já existentes e reformadas, se tornam a principal instituição de produção de ciência, tecnologia e inovação como sugere Magalhães (2006). Mais uma vez a narrativa moderna sobre a Universidade é reafirmada - se criam universidades atreladas ao Estado, visando o

1 Vale lembrar que no século XIX, no Brasil, estavam sendo criadas as primeiras universidades profissionais 
desenvolvimento nacional com base na produção de ciência - e alterada, quando tecnologia e inovação ganham força.

A narrativa da universidade moderna sobrevive ainda no século XXI, porém sob mais um influxo reformador: o da razão neoliberal, a hegemônica "nova razão do mundo" (LAVAL; DARDOT, 2009), "forma atual do capitalismo que se impõe em todo o lugar" (LAVAL; DARDOT, 2015, p. 297), inclusive nas universidades.

A razão neoliberal impõe novas fissuras à narrativa da Universidade Moderna sem, no entanto, destituí-la. A educação, o fazer ciência são reconfigurados, uma vez que o próprio Estado é reformado sob critérios concorrenciais da esfera privada produtiva. A concorrência e a competição são alçadas em motores das relações, pela mudança no arcabouço jurídico. $\mathrm{O}$ Estado foi e é fundamental no espraiamento da lógica empresarial neoliberal, para toda a sociedade. Como afirmam Laval e Dardot (2015.) sobre o papel do Estado:

Com o neoliberalismo a questão é outra, e ela substitui a dos limites: não se trata de limitar, mas de expandir. Nesse caso, é necessário estender a lógica do mercado para além da esfera estrita do mercado e, para isso, reformar o funcionamento interno do Estado de modo a torná-lo a alavanca dessa extensão. O Estado neoliberal é "governamentalizado", no sentido de que os novos dispositivos institucionais que o distinguem visam criar situações de concorrência, introduzir lógicas de escolha, desenvolver medidas de desempenho, cujo efeito é modificar a conduta dos indivíduos, mudar sua relação com as instituições e, mais precisamente, transformá-los em consumidores e empreendedores. As políticas educacionais e acadêmicas são exemplos perfeitos dessa dinâmica. (grifos nossos)

De novo, a narrativa da Universidade Moderna é reafirmada, porém torna-se um importante dispositivo de espraiamento do neoliberalismo, que impõe a sociabilidade rentista, do resultado, da performance. Na universidade, a avaliação e a gestão mercantil atrelados à linhas de financiamento, são os principais dispositivos para a formação da nova sociabilidade. É vasta a bibliografia sobre os efeitos nefastos destes dispositivos (ver por exemplo, BORON, 2008 e ZINGANO, 2017), especialmente o da avaliação por resultados medidos em publicações - produtivismo, industrialismo acadêmico -, no fazer ciência dentro da universidade. A banalidade do projeto e do produtivismo acadêmico privatiza, tiraniza e esteriliza o pensamento criativo e autônomo, sufocando a universidade por dentro. O sentido do fazer ciência e desenvolvimento - Estado, ciência e tecnologia para o desenvolvimento - é deslocado da justiça social e igualdade para todos para a apropriação de poucos - privatização, lucro e resultados. O núcleo narrativo se reconfigura no quadro da universidade neoliberal: 
ciência e tecnologia se traduzem em resultado privado que redundará em aumento da lucratividade de empresas e novos financiamentos para a Universidade. A res pública é substituída pela concorrência no mercado.

$\mathrm{Se}$, a narrativa moderna que consubstancia mais recentemente a universidade em torno do Estado-nação, da ciência, da tecnologia e do desenvolvimento, nasce como discurso de liberdade e progresso dos povos, alcança a maturidade servindo à segurança nacional, à tirania e ao genocídio. Se pelo desenvolvimento se pretendia gerar justiça e igualdade, essa ideia também serve à causa da guerra (incluindo a comercial) contra, por exemplo, povos originários, camponeses e países periféricos em que a universidade encontra-se no centro de práticas e discursos legitimadores dessas ações.

Nesse momento crítico da crise estrutural do capital, os recursos naturais, ecológicos e energéticos são disputados de forma acirrada e violenta. Na América Latina a agroecologia, a agricultura familiar, os pequenos produtores, os trabalhadores rurais e urbanos, os povos originários, ocupam a linha de frente das vítimas dramaticamente afetadas nas suas condições de vida, tendo em vista a importância das commodities na disputa capitalista internacional. (LEHER. 2015, p.14). A violência do processo coloca em risco a própria vida no planeta.

Num cenário de destruição de conhecimentos e ataques aos povos originários e camponeses, a atuação da Universidade junto a essas populações assume relevância científica, política e social, no entanto ela é desautorizada pelos dispositivos neoliberais que valorizam a relação rentista da ciência-tecnologia com o setor produtivo lucrativo e a produção de papers. A luta pela posse e manutenção da terra e dessa população na terra, a defesa e prática da agroecologia, dos conhecimentos ancestrais são aspectos que, nesse momento, demarcam um espaço tenso da geopolítica do conhecimento. Da perspectiva da Universidade, demandam práticas concretas, que para serem mantidas necessitam se impor na contracorrente do produtivismo e da privatização que caracterizam a universidade neoliberal. Para Leher (2015) os vínculos com os movimentos sociais são essenciais, tendo em vista a constante necessidade de análises mais aprofundadas que desvelem os desdobramentos da crise estrutural do capital com o que a Universidade pode contribuir, e, de outro lado, a contribuição dos movimentos sociais para a construção de uma outra Universidade.

A universidade "moderna neoliberal" revela o centro da disputa, se considerarmos a geopolítica do conhecimento, na crise estrutural do capital. Nesse sentido vale trazer a análise de Visvanathan (2006). Num exemplo citado pelo autor, ele relata a tragédia dessa narrativa 

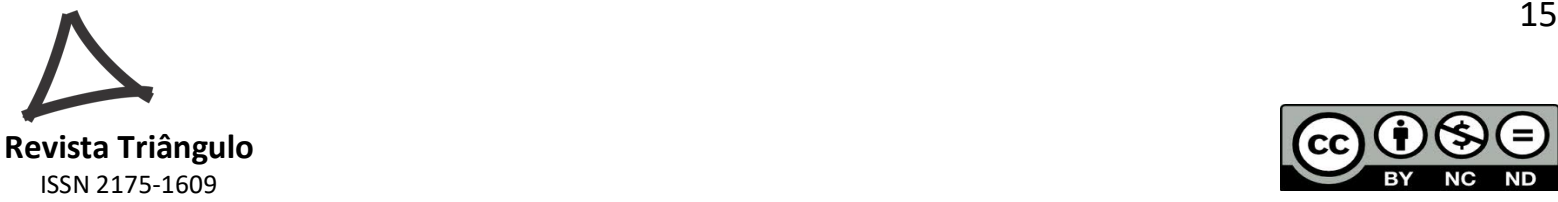

moderna sobre o binômio Universidade-ciência para os indianos, que resultou na agressão e destruição do seu frágil sistema ecológico e da representação de mundo a ele relacionado, em consequência da construção de barragens. Outro exemplo que vale tanto para o caso da Índia como dos países latino americanos é a chamada "Revolução Verde", que agride o meio ambiente e obriga milhares de camponeses a migrar para os aglomerados urbanos expulsos de suas terras. Nesse sentido, a ciência como norma, associada à cadeia de transferência tecnologia-inovação, impõe o desenvolvimento como sentido, na banalidade dos projetos, metodologicamente esboçados pelas agências de fomento. Visvanathan (2006) parafraseando Arendt, indica a tirania contida neste encadeamento, que se naturaliza pela repetição cotidiana do mecanismo que "mata" a produção de conhecimento para a Vida. A "banalidade dos projetos" contém em si a determinação dos critérios do pensar-verdade, do lugar de produção científica e o lugar de seu espraiamento, momento em que pensar cientificamente se torna forma hegemônica de ser e estar no mundo, pela disseminação da tecnologia atrelada aos circuitos comerciais e lucrativos:

A cadeia de inovação enquanto sequência estruturada é uma tentativa de ligar a ciência, a tecnologia e a sociedade por meio de sequências de invenção, inovação e desenvolvimento. Citando o discurso oficial dos manuais ${ }^{2}$, a invenção representa a criação de uma ideia científica e a sua visualização inicial como produto tecnológico; a inovação, a comercialização e divulgação de uma ideia e a sua consequente absorção ou distribuição na sociedade em geral. Poderia afirmar-se que a ideia de inovação não é apenas um discurso de gestão de investigação, mas um discurso sobre o desenvolvimento e a democracia. (VISVANATHAN, 2006, p. 761)

Ou seja, os manuais continuam a disseminar uma visão linear do processo de produção científica e tecnológica, do desenvolvimento, do bem estar, da justiça e da própria democracia, além de reforçar os cânones científicos como critério de verdade e a Universidade como seu lugar de realização privilegiada. Visvanathan (2006, p. 761) indica a geopolítica dessa perspectiva:

Num sentido geográfico, a ciência tem origem no centro e o desenvolvimento ocorre na periferia. Trata-se também de uma visão tecnológica da democracia, em que a ciência é legitimada por especialistas mas consumida por cidadãos. A participação, as matérias e as perspectivas locais surgem das fases mais avançadas da cadeia de inovação. A organização cívica da transferência de tecnologia representa um mapa de políticas, um modelo de hegemonia, uma visão do conhecimento e uma metáfora da democracia. A ciência e a

20 autor se refere ao Banco Mundial. 
democracia apresentam o seu repertório de possibilidades no âmbito de uma cadeia de inovação. Há assim uma sensação de futuros tornados impossíveis, porque, nas visões oficiais, a alternativa ao desenvolvimento não é o desenvolvimento alternativo e sim a "museologização" e a marginalização.

$\mathrm{Na}$ Índia como no continente latinoamericano projetos de desenvolvimento, cientificamente fundamentados, marginalizam e destróem populações e seus conhecimentos ancestrais, nos quais a natureza não é apenas um objeto ou recurso, mas faz parte de um determinado modo de vida. Um modo de vida que corresponde a um modo de conhecimento altamente complexo, que não se expressa na lógica dualista observador/observado, sujeito/objeto, entranhada na ciência moderna. Ao contrário, é um conhecimento que integra árvores, plantas, animais, os rios, os ventos, o tempo, os astros, a terra, além do ser humano. Trata-se de uma cosmovisão, como indica Visvanathan (2006), informando também que na Índia a crítica à ciência moderna não nasceu na universidade e sim de "activistas dos direitos humanos, de ecologistas e de feministas que lutam contra o fundamentalismo da ciência oficial representada pela transferência tecnológica" (p. 760).

Mas, o problema do desenvolvimento assim colocado nos remete a face ocultada pela narrativa da Universidade moderna, abrindo possibilidades que foram historicamente negadas. A crise de 2008 só aprofundou o neoliberalismo associado, agora, ao seu aprofundamento, processo que nos remete aos aspectos geopolíticos indicados por Mészáros (2002 e 2007) quanto a irreformabilidade, incontrolabilidade e destrutividade do capital. A expansão do capital a cada crise de acumulação, ou seja, a reestruturação da economia, como a denomina Mészáros (2002), funda-se, especialmente após a segunda guerra mundial, em fatores irreconciliáveis: o desemprego estrutural e a superprodução; os gastos crescentes com o complexo militar-industrial e o acirramento do conflito capital e trabalho; e, finalmente, a industrialização do "terceiro mundo" que traz complicações competitivas ${ }^{3}$. A competição do terceiro mundo desenvolvido, ou das ilhas de tecnologia e desenvolvimento no terceiro, também são destruídos. As tentativas de reorganizar a economia dentro dos moldes do capital financeiro, esbarram com seus próprios limites muito rapidamente. A mais recente dessas tentativas resultou na crise de 2008, mote para mais um conjunto de ataques aos direitos sociais que vão dissipando a ilusão conciliatória acalentada pelas conquistas do pós segunda

${ }^{3}$ As análises de Mészáros sobre essas características encontram-se entre as páginas 1072-1075 da referida obra. 
guerra mundial, dentre elas, a ideia de que mais ciência e tecnologia resultam em desenvolvimento e bem estar para os povos.

Ao mesmo tempo, o cenário atual exige que se recoloque a questão do desenvolvimento dentro de outros padrões - desenvolvimento alternativo. Num mundo em que a precariedade se torna regra, os movimentos antiglobalização denunciam os novos sentidos e significados das lutas políticas impulsionadas pelo crescente empobrecimento e precarização da Vida. Se a razão neoliberal acentuou o distanciamento entre a Universidade e as classes populares, entre ciência e conhecimento popular, devido aos processos de crescente burocratização, privatização e, em alguns casos, como deslegitimação da atuação "militante" do acadêmico, a irrupção de um novo ciclo de mobilização social pode reavivar os vínculos e aproximar alta cultura e cultura popular, como a denominam Santos (1997).

Assim é que se pode entender a tensão entre Universidade e classes populares e o significado do conceito de mobilização do conhecimento que trataremos na sequência.

\section{A MOBILIZAÇÃO DO CONHECIMENTO}

A relação entre a Universidade e as classes populares também suscita questões sobre a significação social dessa instituição. Esta relação pode ser considerada alternativa tendo em conta os dispositivos presentes na Universidade neoliberal, nesse momento de aprofundamento das contra reformas. Nesse cenário, a relação com as classes populares e os movimentos sociais pode constituir-se como uma alternativa na reconfiguração narrativa da significação social da universidade, especialmente a latinoamericana.

É dessa perspectiva que apresentaremos a seguir a ideia de mobilização do conhecimento, que surge no Canadá, como indicam Naidorf e Perrota (2015), trazido pelo Social Sciences and Humanities Research Council (SSHRC) e incorporado para avaliar os impactos das pesquisas nas áreas das ciências sociais e humanas. Desta perspectiva canadense para a mobilização do conhecimento, é necessário que o conhecimento seja útil, multidirecionado e que deve mover-se entre os diversos atores sociais, entre diversos setores acadêmicos, sociais, públicos e privados, de maneira dinâmica. Ou seja, nota-se a mesma geopolítica indicada por Visvanathan (2006) em que o movimento de produção - central - e sua circulação - periférica- trazem a democratização do conhecimento. Identifica-se a perspectiva técnico-pragmática na proposta do SSHRC canadense que implica o risco da 
utilização e manutenção das ciências sociais como legitimadoras de explicações técnicas e gerenciais para problemas políticos.

Naidorf e Perrota (2015) problematizam e ampliam o conceito com a contribuição de cientistas como Varsavsky que propuseram a politização da ciência latinoamericana considerando a politização dos cientistas, tendo em vista que são os principais atores que produzem ciência. Varsavsky, segundo Naidorf e Perrita (2015), utiliza o conceito para propor uma consciência da ciência como bem público que seja produzida para resolver necessidades sociais. Nesse sentido, vale a pena citar também a contribuição da chamada ELAPCYTED - Escuela Latinoamericana de Pensamiento en Ciencia, Tecnología y Desarrollo (Vidal e Mari. 2002), cujas principais ideias ${ }^{4}$ podem ser sintetizadas no seguinte: 1- A tecnologia como "um pensamento que nasce da prática" (p.9) já que é elemento que deve ser "vivenciado". 2- Implica um rompimento prático com o modelo linear por oferta, em que os conhecimentos gerados não respondem a uma demanda. Ao contrário, para os cientistas que durante os anos de 1950 até 1970 podem ser identificados como da ELAPCYTED, tudo ocorria ao contrário, partindo da demanda social para o fazer científico. (VIDAL e MARI, 2002). 3- A busca do desenvolvimento tecnológico próprio para os países periféricos, em que o essencial é criar autonomia na tomada de decisões.

A contribuição dessas perspectivas politizadas sobre a ciência ampliam o conceito de mobilização do conhecimento proposto inicialmente no Canadá, pois indicam, por exemplo, a necessidade de pensar o fazer científico a partir de demandas sociais o que implica também em considerar o conhecimento científico no mesmo patamar não hierarquizado, com outros saberes. No entanto, essa perspectiva está atrelada ao nacional desenvolvimentismo dos anos 50-70, o que, no cenário atual pode significar limites.

Mais recentemente Naidorf; Pérez Mora; Rios (2018, p.39) concebem a mobilização do conhecimento como:

El campo de estudios que promueve la comprensión de las políticas científicas orientadas al impacto social de la investigación científica, al análisis de su uso social, al estudio de los temas estratégicos, los mecanismos de evaluación que orientan las prácticas de $1 x(e) s$ científicx(e) s y los mecanismos que influencian la toma de decisión en torno a las agendas y su foco en la solución de problemas sociales.

${ }^{4}$ Apresentamos essas ideias mais detalhadamente em Monfredini (2015).

\begin{tabular}{l|l|l|l|l|l} 
(C) Revista Triangulo & Uberaba, Minas Gerais & v.11 & n.4-Esp. & p. $150-167$ & 2018
\end{tabular}


Este é um conceito em construção e que, nesse sentido, indica um campo de estudos. A reflexão sobre a mobilização do conhecimento exige o aporte de conceitos específicos que auxiliem a problematizar e identificar possíveis vertentes para realização dos processos de produção científica, considerando a relação da universidade com o "extra muros ${ }^{\text {ee }}$ universitário latino-americano.

Um desses autores é Santos (2011, p. 42), que, ao tratar da relação entre a Universidade e a Sociedade, sugere a ideia de conhecimento pluriversitário, contextual na medida em que "o princípio organizador da sua produção é a aplicação que lhe pode ser dada". Este se contrapõe ao conhecimento universitário em que a Universidade produz o conhecimento que a sociedade aplica. A leitura de Santos sugere que, na atual crise da Universidade, a tendência é de ampliação de espaços de produção de conhecimento pluriversitários, advertindo que "o conhecimento pluriversitário tem tido a sua concretização mais consistente nas parcerias universidade-indústria e, portanto, sob a forma de conhecimento mercantil" (SANTOS, 2011, p. 43). A leitura de Santos (2011) sugere ainda que, como tipos ideais, o conhecimento universitário e o pluriversitário realizam-se contraditoriamente, o que nos permite vislumbrar também possibilidades. Como afirma Santos (2011, p. 43):

Mas, sobretudo nos países centrais e semiperiféricos, o contexto de aplicação tem sido também não mercantil, e antes cooperativo, solidário, através de parcerias entre pesquisadores e sindicatos, organizações não governamentais, movimentos sociais, grupos sociais especialmente vulneráveis [...].

A análise mais aprofundada do conceito exige considerar a dinâmica relação entre poder e conhecimento desconstruindo qualquer consideração estática acerca dessa distribuição. Mobilização do conhecimento propõe, ao contrário, o dinamismo gerado na relação universidade e classes populares, para sua produção apropriação e uso. Esse é o tema que será tratado na sequência, finalizando este artigo.

\section{NOVAS EPISTEMOLOGIAS, PODER E MOBILIZAÇÃO DO CONHECIMENTO}

A discussão anterior nos leva a reconhecer que a distribuição espacial do conhecimento, sem dúvida, tem um peso que implica questões epistêmicas e políticas. Longe das posições que supõem um conhecimento universal e objetivo, podemos afirmar que as condições geopolíticas do lugar de geração de conhecimento têm implicações em sua 
natureza. Há um senso de legitimação geopolítica do conhecimento. Historicamente, o eurocentrismo teve forte impacto no reconhecimento do conhecimento central com a consequente exclusão e deslegitimação de outros conhecimentos. "A América Latina, foi fabricada como algo deslocada da modernidade, um movimento que assumiu os intelectuais e estadistas latino-americanos e se esforçaram para torná-la "moderna "como se" a "modernidad" fuera un punto de llegada y no la justificación de la colonialidad del poder" (WALSH, 2003, p.2). Diante dessa realidade é necessária a reflexão sobre a relação entre poder e conhecimento, a reflexão que servirá para apoiar a nossa tese sobre o potencial da categoria de "mobilização do conhecimento" como uma alternativa para romper com o pensamento hegemônico colonialista e imperialista.

A distinção feita por Slater (2008, p. 338) entre poder "sobre" e poder "para" nos permite problematizar a relação macro-micro na configuração do poder. O autor defende a postura de que existem diferenças entre ambos, mas sobretudo enfatiza em suas conexões "El poder sobre está asociado con un estado de dominación en el cual el agente es capaz de ejercer influencia que repercute sobre otro agente (o sujeto social) y en el que las relaciones de poder se caracterizan por una cierta rigidez, de tal manera que pueden aparecer congeladas en el tiempo y en el espacio" (SLATER, 2008, p. 338). Desta perspectiva a estrutura se impõe sobre os sujeitos. Existe un determinismo que opera en relación a una gama de asuntos que abarcam desde as estruturas macro, como são as grandes transnacionais, a economía e/ou o estado, até certas organizações ou instituições sociais como a escola, o hospital e o manicômio, as quais se configuram como as grandes forças de definição e imposição do poder. Por otro lado, o poder para pode se referir "a la habilidad de resistir o contrapasar la influencia del otro, especialmente demostrada en los efectos de la acción colectiva y movimientos sociales radicales" (idem).

Por otro lado, Popkewitz utiliza a noção de poder como soberania opondo-se à noção de poder como efeitos. A primeira destaca as relações desiguais entre os diferentes atores, a segunda é a noção produtiva de poder, isto é, a implantação do poder para produzir a vontade do conhecimento. O primera refere-se a grandes estruturas históricas através das quais a vida cotidiana é construída, o segundo enfoca os micropolítica onde as subjetividades são construídas. (POPKEWITZ, 1994, p. 7). A noção de poder como soberania leva à reflexão para identificar quais grupos são favorecidos pelos processos decisórios e como tais decisões distribuem valores para produzir um contexto de dominação e subordinação, nesse sentido 
essa noção ao colocar a ênfase na identificação de estruturas de poder, não é capaz de apreciar teoricamente os elementos produtivos do poder. A noção é identificada com uma posição historicamente utilizada por grupos de poder para manter e legitimar o status quo para o qual o autor nos convida a entendê-la "como noción contingente acerca de cómo el poder se presenta en lugar de entenderlo como categoría estructural acerca de cómo el poder reprime" (POPKEWITZ, 1994, p.8)

A relação entre poder sobre e poder para, ou entre poder como soberania ou poder como efeitos, tem implicações políticas e epistemológicas, daí a importância de se analisar tanto a fonte de poder quanto a fonte de conhecimento, dois aspectos intimamente interligados. Foucault assinalava que "no hay relación de poder sin la constitución correlativa de un campo del conocimiento" (FOUCAULT, 1979, in: SLATER, 2008, p.339). Para a análise das fontes de poder e conhecimento é necessário reconhecer que tanto poder como conhecimento são construções sociais. A partir dessa perspectiva, podemos visualizar o potencial dos setores historicamente considerados como "externalidades" ou "excluídos" na construção do poder e do conhecimento. A força de ambos reside no apoio fornecido pelas estratégias de legitimação que são acompanhadas por práticas de subordinação que são mais frequentemente legitimadas e aceitas pelos mesmos setores que estão subordinados.

O poder é exercido tanto na produção de conhecimento quanto na mobilização e uso. Poder que se manifesta pela determinação dos atores, dos temas, dos lugares autorizados e legitimados por ele.

\section{CONCLUSÕES}

As diferenças geopolíticas e as estratificações sociais existentes em torno da distribuição do poder e do conhecimento apresentam grandes desafíos para as universidades. Estas instituições, que são em grande medida a determinadas por suas condições históricas e geopolíticas, são por sua vez instituições que tem uma grande responsabilidade por gerar estratégias para transformar essas condições. O conhecimento é um fator importante na conformação dessas estruturas e, no mesmo sentido, é um elemento que abre as possibilidades de transformação. Conceber o conhecimento como algo dinâmico e móvel permite gerar equilíbrios entre os determinismos macro com as possibilidades de construções a partir do micro, desde o local e particular. É possível e desejável que se promova a geração do 
conhecimento rompendo as lógicas lineares centro-periferia. O conhecimento tem um enorme potencial de crescimento se são reconhecidos os saberes gerados nos setores tradicionalmente deslocados e excluídos. A Universidade deve promover a transição a uma sociedade com um melhor equilíbrio na distribuição do poder e do conhecimento, -dois elementos intimamente ligados-, tarefa que, acreditamos, pode ser impulsionada por meio de estratégias de democratização, de inclusão social e da promoção dos diálogos de saberes. Para isto, a categoria de mobilização do conhecimento pode aportar ferramentas substanciais e, neste sentido, a universidade, em colaboração com os setores sociais públicos e privados, tem uma grande responsabilidade para impulsionar seu desenvolvimento.

\section{REFERÊNCIAS}

BORON, Atilio A. Consolidando la Explotación. La academia y el banco Mundial contra el pensamiento crítico. Córdoba: Espartaco, 2008.

DUBE, S. Introducción: cuestiones acerca de las modernidades coloniales. In: Modernidades coloniales: otros pasados, historias presentes. México: El Colegio de México A. C. 2004, p. $13-48$.

DUSSEL, E. Sistema-mundo y transmodernidad. In Modernidades coloniales: otros pasados, historias presentes. México: El Colegio de México. 2004, p. 201-226.

FOUCAULT, M. Microfísica del poder. 3. ed. Madrid: Las Ediciones de la Piqueta, 1992.

GROSFOGUEL, R. Colonial difference, geopolitics of Knowledge, and global coloniality in modern/colonial capitalist world-system. Review Fernand Braudel Center. Rechearch Foundation of State University of New York, 25(3), 2002, p. 203-224.

LEHER, Roberto. Movimentos Sociais, padrão de acumulação e crise da universidade. Trabalho para o GT 11. In: 37 a Reunião Nacional da ANPEd - 4 a 8 de outubro de 2015, UFSC - Florianópolis, 16p. 2015. Disponível em: http://www.anped.org.br/biblioteca/item/movimentos-sociais-padrao-de-acumulacao-e-criseda-universidade Acesso em: 8 Jul. 2017.

MAGALHÃES, A. M. A identidade do ensino superior: a educação superior e a universidade. Revista Lusófona de Educação, 7, 2006, p. 13-40.

MignolO, W. D. Capitalismo y geopolítica del conocimiento. In Modernidades coloniales: otros pasados, historias presentes. 1st ed. México: El Colegio de México A. C. 
2004, p. 227-260.

MONFREDINI, I. Ciência para Inclusão Social no Brasil: uma análise crítica. In: Sinéctica Revista Electrónica de Educación, v.44, 2015, p.1-19.

MORIN, E. El método IV. Las ideas. Su hábitat, su vida, sus costumbres, su organización. Madrid: Catedra, Teorema, 2001.

PÉREZ MORA, R., CRUZ SÁNCHEZ, G. N., \& GARCÍA PONCE DE LEÓN, O. Las condiciones y retos para la movilización del conocimiento en México. Revista Lusófona de Educação, 39 (39), 2018, p. 97-111.

PÉREZ MORA, R., \& INGUANZO ARIAS, B. Li. La movilización del conocimiento en las políticas científicas en México. Revista Horizontes Sociológicos, 5 (Julio-Diciembre), 2018, p. 69-81.

POPKEWITZ, T. S. Política, conocimiento y poder: algunas cuestiones para el estudio de las reformas educativas. Revista de Educación, (305), 1994, p. 1-29.

SANTOS, B. de S. Pela mão de Alice: o social e o político na pós-modernidade. 4. ed. São Paulo: Cortez, 1997.

SLATER, D. Re-pensando la geopolítica del conocimiento: reto a las violaciones imperiales.

Tabula Rasa, 8 (Enero-Junio), 2008, p. 335-358.

VISVANATHAN, Shiv. Convite para uma guerra da ciência. In: SANTOS, B. de S. (org.).

Conhecimento prudente para uma vida decente. 2. ed. São Paulo: Cortez. 2006.

WALSH, C. Las geopolíticas del conocimiento y la colonialidad del poder. Entrevista a Walter Mignolo. Polis. Revista Académica Bolivariana, 1 (4), 2003, p. 1-26.

ZINGANO. Marco. Sobre o qualis periódicos 2015- Filosofia e o risco de sepukku. In:

Revista ADUSP. Revista no.60-maio/2017. Acesso via http://www.adusp.org.br/index.php/imprensa/revista-adusp/2872-maio-2017 em 8 Jun. 2017. 